\title{
A CULTURA NO PENSAMENTO (E NA AÇÃO) DE CELSO FURTADO: DESENVOLVIMENTO, CRIATIVIDADE, TRADIÇÃO E INOVAÇÃO
}

ENSAIOS SOBRE CULTURA E O MINISTÉRIO DA CULTURA.

Furtado, Celso. Rio de Janeiro: Contraponto, 2012.

GEORGE KORNIS

Ensaios sobre cultura e o Ministério da Cultura, organizado por Rosa Freire d'Aguiar Furtado, é o quinto volume da série Arquivos Celso Furtado e contém muitas informações sobre o pensamento de Celso Furtado (1920-2004), um intelectual que teve a ousadia de ultrapassar os limites disciplinares em favor da construção de uma dicção autoral. Furtado foi um homem de pensamento e ação que circulou por distintos territórios, da vida universitária a órgãos de governo, além de transitar por organismos internacionais e nacionais. Essa publicação, que reúne um conjunto bastante diversificado e pouco conhecido de textos (documentos, artigos e entrevistas), apresenta o autor como intelectual, homem público e um brasileiro de projeção internacional.

O foco do livro é (in)formar os leitores sobre o pensamento de Celso Furtado no campo da cultura - campo sobre o qual ele se debruçou ao longo de várias décadas. No entanto, essa reflexão ainda não é percebida, sobretudo no meio acadêmico, como um vetor importante de sua obra.

O pensamento desse intelectual tem hoje uma presença ainda limitada na universidade brasileira. De modo geral, restringe-se às (boas) faculdades de economia, que, do amplo espectro da obra do autor, utilizam pouco além do clássico Formação econômica do Brasil, publicado originalmente em 1959. Assim, para ter uma maior presença na universidade brasileira, o pensamento de Furtado - que está ainda muito circunscrito ao campo da história econômica e do desenvolvimento econômico - depende diretamente da percepção do seu caráter multidisciplinar.

Naintroduçãodolivro aqui resenhado, Rosa Freire d'AguiarFurtado delimita os quatro momentos da extensa reflexão de Furtado no campo da cultura. O primeiro deles data dos anos 1970 e sua obra síntese é o 
livro Criatividadee dependência na civilização industrial, publicado originalmente em 1978. O segundo momento situa-se no período compreendido entre 1986 e 1988, quando Furtado foi ministro da Cultura no governo Sarney. O terceiro diz respeito ao período compreendido entre os anos de 1992 e 1995, quando a Comissão Mundial de Cultura e Desenvolvimento (CMCD) da ONU/Unesco reuniu, além de Furtado, um conjunto de intelectuais do porte de Amartya Sen (Prêmio Nobel de Economia/1998) e Elie Wiesel (Prêmio Nobel da Paz/1986). O quarto e último momento se dá em 1997, quando Furtado ingressa na Academia Brasileira de Letras, instituição na qual profere um conjunto de conferências cujos textos integram a coletânea em análise.

O bloco "Documentos de Celso Furtado" é, sem dúvida, a parte mais consistente da publicação. Ele contém 23 textos subdivididos em quatro tópicos intitulados "Primeiras reflexões", "O Ministério da Cultura", "A Comissão Mundial de Cultura e Desenvolvimento" e "Páginas acadêmicas". Esse conjunto central é sucedido por dois outros blocos que lhe são complementares. O primeiro, intitulado "Artigos", consiste em dois textos de autoria de dois importantes dirigentes culturais durante a gestão de Furtado do Ministério da Cultura (MinC): Ângelo Oswaldo de Araújo Santos, chefe de gabinete do MinC, e Fábio Magalhães, secretário de Apoio à Produção Cultural do MinC e presidente da Funarte. Ambos são textos de caráter documental que podem legitimamente ser considerados complementares aos textos do tópico específico "O Ministério da Cultura".

O bloco seguinte é composto de duas entrevistas com Celso Furtado: a primeira, realizada em 1987, foi conduzida por duas pesquisadoras francesas - Hélène Rivière d'Arc e Hélène Le Doaré do Comité National de la Recherche Scientifique (CNRS) e do Centre de Recherche et Documentation sur L'Amérique Latine (CREDAL/ Paris); a segunda, realizada no ano anterior, coube a Gabriela Marinho e foi publicada na revista Arquitetura e Urbanismo. Na primeira entrevista Celso Furtado retomou elementos centrais de seu pensamento tais como as categorias de desenvolvimento, de criatividade, de cultura (em especial de política cultural e de economia da cultura) e de identidade cultural e, nessa perspectiva, ela é ainda hoje um documento importante.

O bloco "Documentos de Celso Furtado" inicia-se com o tópico "Primeiras reflexões", que reúne dois textos: o interessante "Que somos?" - no qual o autor aborda os temas da identidade e da cultura brasileira e ainda tangencia Schumpeter ao relacionar crise a criatividade - e o vigoroso "Criatividade cultural e desenvolvimento dependente" - um trabalho exploratório que, segundo a organizadora, é a "primeira versão de um dos ensaios de Criatividade e dependência na civilização industrial", livro-chave da obra de Furtado. 
O primeiro texto é a conferência proferida no I Encontro Nacional de Política Cultural, ocorrido em Belo Horizonte em abril de 1984. Nesse momento, o Brasil estava próximo de operar a passagem da mais longa ditadura militar da história do país (1964-1985) para uma restauração da ordem democrática sem a presença de eleições diretas para a presidência da República. A dificuldade dessa transição política ampliava-se no quadro de uma desaceleração do crescimento econômico em paralelo a uma intensificação inédita do processo inflacionário. Nesse contexto os secretários estaduais de Cultura, somados a vários dirigentes de instituições culturais das três esferas de governo e a um grande número de artistas e intelectuais, acreditavam que a criação do Ministério da Cultura - em substituição a uma Secretaria de Cultura vinculada ao Ministério da Educação e Cultura — seria um importante vetor da reconstrução democrática do país. Nessa perspectiva destaca-se a relevância da afirmação de Celso Furtado — proferida por um intelectual nacional-desenvolvimentista e ex-ministro do governo Goulart, deposto pelo golpe militar de 1964 - segundo a qual "uma reflexão sobre a nossa própria identidade terá de ser o ponto de partida do processo de reconstrução que temos pela frente, se desejamos que o desenvolvimento futuro se alimente da criatividade do nosso povo e contribua para a satisfação dos anseios mais legítimos desse". O mesmo texto trouxe uma contribuição igualmente importante ao apresentar sete teses sobre a cultura brasileira, que consistem, na verdade, numa visão panorâmica e histórica do processo cultural brasileiro do século XVI até o final do século XX, quando a indústria da cultura passava a atuar como instrumento da modernização dependente do país. E não menos importanteé a referência, ao final, de breve e precisa reflexão sobre política cultural, cujo centro é a afirmação de que "o objetivo central de uma política cultural deveria ser a liberação das forças criativas da sociedade", as quais deveriam interagir com as forças produtivas. Furtado apontava assim para a necessária interação entre cultura enquanto sistema de valores (que definem os fins) e o desenvolvimento das forças produtivas (que definem os meios), ou, noutros termos, a necessária interação entre identidade (cultural) e potência (produtiva).

O segundo artigo, datado da segunda metade dos anos 1970, como foi dito, é uma versão preliminar de um ensaio que integra o livro Criatividade e dependência na civilização industrial, no qual Furtado demonstra sua singularidade como economista, ao introduzir, de modo inovador, a dimensão cultural na questão do desenvolvimento. Segundo Rosa Freire d'Aguiar Furtado, o desenvolvimento, para esse autor, "seria menos o resultado da acumulação material do que um processo de invenção de valores, comportamentos, estilos de vida, em suma, de criatividade". 
O tópico subsequente, "O Ministério da Cultura", apresenta nove textos escritos entre fevereiro de 1986 ejulho de 1988 , período no qual Celso Furtado foi o titular da pasta da Cultura, sucedendo a José Aparecido de Oliveira - o primeiro ministro da Cultura, que permaneceu no cargo somente por dois meses, em 1985 - e a Aluísio Pimenta - que passou apenas pouco mais de oito meses no exercício da função. Sua permanência à frente do ministério, com duração de dois anos e cinco meses, foi das mais longevas da história dessa pasta, tendo sido superada apenas por Francisco Weffort (1995-2002) e Gilberto Gil (2003-2008). A alta rotatividade dos titulares de um Ministério da Cultura recém-criado é um dado contextual que não pode ser desconsiderado quando da leitura dos textos de Furtado, escritos quase sempre com brevidade e urgência para expressar seu pensamento e ação.

Um desses textos foi seu discurso de posse. Afirmava naquele momento que o desafio não era apenas preservar o passado, mas transformá-lo em fonte de criatividade no presente e no futuro. $\mathrm{O}$ então ministro se apresentava como consciente de que "a revolução nas tecnologias de comunicação está modificando profundamente a problemática da cultura" e que ela conduz à massificação e à hipertrofia do mercado. Assim, para ele e seus colaboradores, "a política cultural, em face da revolução das tecnologias de comunicação, terá de preocupar-se não apenas em democratizar o acesso aos bens culturais, mas também em defender a criatividade".

No texto "Economia da cultura", Furtado tratou brevemente de um tema tão importante quanto até hoje relativamente pouco elaborado no Brasil, apesar de objeto de reflexão de importantes economistas norte-americanos e europeus desde os anos 1960. Furtado, na década de 1980, estava consciente desse atraso bem como da necessidade de sua superação. Nesse sentido, é importante destacar que seu texto é uma breve introdução ao estudo "Economia e cultura: reflexões sobre as indústrias culturais no Brasil", realizado pela Fundação João Pinheiro, em 1988. A despeito de todos os seus limites, "Economia da cultura" e o estudo acima citado foram iniciativas pioneiras na abordagem do processo de produção, distribuição e consumo de bens e serviços culturais no país.

Os vínculos existentes entre desenvolvimento econômico e social e política cultural são apontados no texto "Pressupostos da política cultural". Aqui o pensamento de Furtado revela-se com clareza ao afirmar que "o que chamamos de política cultural não é senão um desdobramento e um aprofundamento da política social". Demonstra aqui a preocupação em articular as políticas econômica (cuja tônica é a acumulação), social (cujo foco é a inserção) e cultural (cujo essencial é a criatividade e a consequente transformação), ou seja, estabelece os 
elos entre os meios e os fins do processo de desenvolvimento. Ao privilegiar as articulações políticas e institucionais, seu pensamento também destaca a ação do Estado que "longe de se substituir à sociedade aplica-se em criar as condições que propiciem a plenitude das iniciativas surgidas dessa sociedade [...] concentrando esforços [na] preservação do patrimônio e da memória culturais, [no] estímulo à criatividade de nosso povo, [na] defesa da identidade cultural do país $e$ [na] democratização do acesso aos valores culturais".

Em outro texto intitulado "O IPC, cultura e desenvolvimento tecnológico", Furtado revelava sua preocupação com a estruturação do próprio ministério. Trata-se de discurso proferido em 1986, na abertura de seminário interno do Instituto de Promoção Cultural, órgão criado com a missão de desenvolver um pensamento no campo da economia da cultura e com função estratégica durante sua gestão. Faz-se aqui presente o estrategista político, que centra seu pensamento de curto e longo prazo no Estado e na cultura enquanto um processo produtivo. Como expressão de um pensamento atento para o desenvolvimento tecnológico - e Furtado chega a mencionar a necessária articulação política com o Ministério da Ciência e Tecnologia -, o mercado e a indústria cultural assumem centralidade.

Um balanço das realizações da gestão Furtado à frente do ministério até fins de 1987 encontra-se no texto "A ação do Ministério da Cultura". Estão ali apresentadas as quatro diretrizes que nortearam sua gestão: a preservação e o desenvolvimento do patrimônio cultural; o estímulo à produção cultural preservando a criatividade; o apoio à atividade cultural onde ela se apresenta como ruptura com respeito às correntes dominantes; e, finalmente, o estímulo à difusão e ao intercâmbio culturais visando democratizar o acesso ao nosso patrimônio e aos bens culturais no país e no exterior. Furtado expõe ainda as realizações de sua pasta, segundo cada uma dessas diretrizes, além das opções feitas por sua gestão. Destaca os programas constituídos por setor de atividade; os compromissos socioculturais são mencionados de modo sistemático; demonstra o empenho em redesenhar instituições com ênfase nas fundações e, finalmente, a Lei Sarney (Lei 7.505, de 2 de julho de 1986) é apresentada grandiosamente como "a grande contribuição prestada pelo atual governo ao desenvolvimento cultural do país". Dedica-se especialmente a esse tema, ao destacaro pioneirismo da criação de uma legislação de incentivos fiscais à cultura, por acreditar que, a partir desse momento, a sociedade civil e, em particular, os empreendedores brasileiros assumiriam iniciativas no campo da produção cultural tendo em vista as limitações de recursos do Estado. Caberia ao Estado gerir tanto o cadastro das entidades às quais é conferido o incentivo, quanto o Fundo de Promoção Cultural. O foco dessa estratégia era "o fortalecimento das atividades empresa- 
riais de interesse cultural de origem e controle nacionais". Ao supor adesões, Furtado possivelmente minimizou a oposição que conduziria à substituição da referida lei, já no governo Fernando Collor, pela Lei no 8.313, de 23 de dezembro de 1991, conhecida como Lei Rouanet.

No texto intitulado "Política cultural e criatividade", fruto de pronunciamento na abertura do Fórum de Secretários de Cultura, realizado em abril de 1987, no qual reiterou a importância da preservação da força criativa do povo brasileiro como fator de identidade cultural, Furtado buscou - talvez com alguma ingenuidade - adesões das Secretarias de Cultura à Lei Sarney, "que tem sido interpretada apenas como um mecenato tradicional embora sua essência seja um convite para que a sociedade participe mais amplamente das iniciativas culturais". No entanto, passado menos de um ano de existência da Lei Sarney, Furtado já identificava de modo arguto "um forte declínio na participação dos recursos destinados à cultura nos orçamentos de muitos estados da federação".

Uma reflexão mais apurada é apresentada em "Política cultural e o Estado", texto datado de fins de 1986, no qual Furtado articula a preservação do patrimônio com inovação e a identidade com democratização do acesso aos valores culturais. Com clareza, há ali uma síntese de seu pensamento: os papéis do Estado e da sociedade civil estão definidos, e temas tais como a descentralização e o desenvolvimento foram devidamente abordados. Trata-se de um documento que foge ao padrão dos discursos comemorativos e dos balanços de gestão para afirmar-se como um arcabouço de um projeto para o desenvolvimento fundado na cultura.

O terceiro tópico do bloco "Documentos de Celso Furtado", denominado "AComissão Mundial de Cultura e Desenvolvimento", compõe-se de dois textos que ajudam na compreensão de seu pensamento no campo da cultura, além de serem bastante consistentes e politicamente relevantes. O primeiro deles, datado de 1994, intitula-se "Economia e cultura" e foi preparado para o projeto preliminar do relatório da CMCD. Trata-se de um texto no qual o pensamento de Celso Furtado é apresentado a partir das seguintes proposições: "a cultura tem que ser observada a um só tempo como processo cumulativo e como sistema"; "se o objetivo fundamental da política de desenvolvimento é melhorar a vida dos homens e das mulheres, seu ponto de partida terá de ser a percepção dos fins, dos objetivos que se propõem alcançar os indivíduos e as coletividades"; "nas sociedades economicamente dependentes a política cultural se faz particularmente necessária [pois] é nela que se manifesta a importância do conceito de identidade cultural que traduz a ideia de manter com o nosso passado uma relação capaz de enriquecer o nosso presente". O segundo texto, intitulado "Cultura e desenvolvimen- 
to" (1995), parte da necessidade de aprofundar as análises e discussões centradas na relação entre cultura e desenvolvimento, avança pela proposição de direitos culturais no desenvolvimento dos direitos humanos e, ao concluir, destaca a importância de princípios éticos e democráticos no curso desse processo.

Já o último tópico desse mesmo bloco, intitulado "Páginas acadêmicas", apresenta um conjunto de dez pequenos textos sobre autores brasileiros que, no entanto, não expressam um vínculo maior com a obra de Furtado nem com as ideias contidas no seu projeto de desenvolvimento centrado na cultura. Uma exceção é o texto de seu discurso de posse, em 1997, na Academia Brasileira de Letras, no qual ele homenageia Darci Ribeiro, homem de pensamento e ação que, como ele próprio, tanto marcou o país. Ambos pertenceram à mesma geração de intelectuais brasileiros, e tiveram em comum o desejo de transformar o país com base em um projeto nacional de desenvolvimento autônomo. Com suas singularidades, Celso Furtado e Darci Ribeiro ocuparam a mesma cadeira na Academia Brasileira de Letras, e suas obras, através do ensino e da pesquisa, podem alimentar novos processos de transformação fundados em projetos de desenvolvimento nacionais e autônomos.

Longe de ser uma compilação voltada para o passado, o livro Ensaios sobre cultura e o Ministério da Cultura é uma fonte contemporânea para reflexão e debate sobre cultura e desenvolvimento. Ademais, ele torna evidente a diversidade e a originalidade do pensamento de Furtado e seu compromisso com uma ação orientada para a mudança social.

GEORGE KORNIS é doutor em Economia, professor associado do IMS/Uerj e autor de diversos trabalhos e pesquisas no campo da economia da cultura. 